\title{
Differential Contributions of the Basolateral and Central Amygdala in the Acquisition and Expression of Conditioned Relapse to Cocaine-Seeking Behavior
}

\author{
Paul J. Kruzich ${ }^{1}$ and Ronald E. See ${ }^{2}$ \\ ${ }^{1}$ The Laboratory of the Biology of Addictive Diseases, The Rockefeller University, New York, New York 10021, and \\ 2Department of Physiology and Neuroscience, Medical University of South Carolina, Charleston, South Carolina 29425
}

The amygdala is known to be a critical mediator of emotional learning in aversive and appetitive conditioning. Here we show for the first time that distinct subregions of the amygdala play unique roles in the acquisition and expression of cocaineseeking behavior maintained by drug-paired cues in a model of relapse. Reversible inactivation of the basolateral amygdala with the sodium channel blocker tetrodotoxin disrupted both the acquisition and expression of the conditioned reinforcing effects maintained by drug-paired stimuli. However, inactivation

The amygdala is a crucial component of the neuronal circuitry mediating associative learning (Everitt et al., 1999; LeDoux, 2000). In particular, the basolateral amygdala (BLA) complex (composed of the basal and lateral nuclei) and the central amygdala $(\mathrm{CeA})$ have been shown to play critical roles in the acquisition and expression of selective forms of associative learning in Pavlovian fear (Miserendino et al., 1990; Gewirtz and Davis, 1997; Nader and LeDoux, 1999) and appetitive (Gallagher et al., 1990; Hatfield et al., 1996; Everitt et al., 1999) conditioning paradigms and to modulate attention to conditioned stimuli (Han et al., 1999; Holland et al., 2000). In these studies, stimuli such as tones and lights were paired with aversive (e.g., shock) or reinforcing (e.g., food) stimuli. These previously neutral stimuli subsequently attain the ability to elicit conditioned responses (such as freezing in fear paradigms and approach responses in appetitive paradigms).

Presentation of stimuli associated with cocaine use (e.g., drug paraphernalia) has been shown to elicit craving in human cocaine addicts (Ehrman et al., 1992). The amygdala, among other brain areas, exhibits increased metabolic activity during cocaine-paired cue presentation in humans (Grant et al., 1996; Childress et al., 1999). In rodent models, BLA lesions disrupted conditioned reinstatement of responding on a cocaine-paired lever (Meil and See, 1997; Grimm and See, 2000) and cocaine-seeking behavior maintained on a second-order schedule of reinforcement (Whitelaw et al., 1996). CeA lesions have been reported to have no effect on the acquisition or expression of associative learning with a sucrose reinforcer, although these lesions did impair the

Received March 29, 2001; revised April 30, 2001; accepted May 7, 2001.

This work was supported by Grant DA-10462 from the National Institute on Drug Abuse. We thank Kimberly Congleton for technical assistance and Dr. Jacqueline McGinty for histology assistance and discussion.

Correspondence should be addressed to Ronald E. See, Department of Physiology and Neuroscience, 173 Ashley Avenue, Medical University of South Carolina, Charleston, SC 29425. E-mail: seere@musc.edu.

Copyright (C) 2001 Society for Neuroscience 0270-6474/01/210001-05\$15.00/0 of the central amygdala disrupted only the expression, but not the acquisition, of the conditioned reinforcing effects of drugpaired stimuli. Our results demonstrate that these nuclei participate as components of an amygdalar circuit to drive cocaine-seeking behavior produced by stimulus-reinforcement associations.

Key words: basolateral amygdala; central amygdala; cocaine; relapse; self-administration; reinforcement potentiation of responding normally seen after intra-accumbens amphetamine (Robledo et al., 1996). Furthermore, lesions of the CeA disrupted conditioned orienting (Gallagher et al., 1990) and Pavlovian-conditioned responses in approach behavior, an effect not seen after BLA lesions (Everitt et al., 1999).

Most experimental paradigms in aversion learning can use one-trial acquisition sessions, making it relatively easy to test the neural substrates of acquisition by pharmacological manipulation at the time of learning, as well as the expression of learning at subsequent time points (Miserendino et al., 1990; Gewirtz and Davis, 1997). Models of appetitive learning with drug selfadministration have not readily approached the issue of acquisition, because multiple conditioning trials are invariably used during self-administration. Furthermore, traditional lesion methods for the study of acquisition are hampered by persisting lesion effects at the time of testing. The present study used a novel associative learning paradigm of relapse to drug seeking, whereby a single session allowed for Pavlovian pairing of cocaineassociated stimuli during the time of chronic drug selfadministration. The reversible sodium channel blocker tetrodotoxin (TTX) was intracranially inf used to test the respective roles of the BLA and the $\mathrm{CeA}$ in both the acquisition and the later expression of cocaine-paired associative learning.

This article is published in The Journal of Neuroscience, Rapid Communications Section, which publishes brief, peerreviewed papers online, not in print. Rapid Communications are posted online approximately one month earlier than they would appear if printed. They are listed in the Table of Contents of the next open issue of JNeurosci. Cite this article as: JNeurosci, 2001, 21:RC155 (1-5). The publication date is the date of posting online at www.jneurosci.org.

http://www.jneurosci.org/cgi/content/full/5433 


\section{MATERIALS AND METHODS}

Subjects and surgery. Male Sprague Dawley rats (300-350 gm) were housed individually and maintained on a $12 \mathrm{hr}$ reverse light/dark cycle. All protocols were approved by an Institutional Animal Care and Use Committee and were conducted in accordance with the National Institutes of Health Guide for the Care and Use of Laboratory Animals (revised 1996). Rats were anesthetized with ketamine $(100 \mathrm{mg} / \mathrm{kg}$, i.p.), xylazine ( $2 \mathrm{mg} / \mathrm{kg}$, i.p.), and Equithesin ( $0.05 \mathrm{ml} / 100 \mathrm{gm}$, i.p.) before surgery. The procedures for catheter construction and implantation have been described previously (See et al., 2001). Briefly, the free end of the SILASTIC (Dow Corning, Midland, MI) catheter was inserted into the right jugular vein and secured with sutures. The guide cannula (Plastics One, Roanoke, VA) of the catheter exited from each rat's back, and a stylet was inserted into the catheter. After catheter implantation, rats were mounted into a stereotaxic apparatus, and stainless steel, 26 gauge guide cannulas $(14 \mathrm{~mm}$ ) were bilaterally aimed $2 \mathrm{~mm}$ above the BLA (anteriorposterior, -2.5 ; lateral, \pm 5.0 ; ventral, -6.6 ) or the CeA (anteriorposterior, -2.0 ; lateral, \pm 4.0 ; ventral, -6.0 ) relative to the skull surface and bregma (Paxinos and Watson, 1986). Stainless steel stylets (32 gauge) were inserted into the guide cannulas after surgery. Rats were inf used intravenously twice daily with $0.1 \mathrm{ml}$ of cefazolin $(10 \mathrm{mg} / 0.1 \mathrm{ml})$ and $0.1 \mathrm{ml}$ of $70 \mathrm{U}$ of heparinized saline during a $4 \mathrm{~d}$ recovery period. Rats received $0.1 \mathrm{ml}$ of $10 \mathrm{U}$ of heparinized saline before each selfadministration session. After each session, rats were administered cefazolin and $70 \mathrm{U}$ of heparinized saline to maintain catheter patency.

Apparatus. Cocaine self-administration and classical-conditioning sessions occurred in standard operant chambers (Med Associates, St. Albans, VT). Intravenous cocaine $\mathrm{HCl}$ (National Institute on Drug Abuse, Bethesda, MD) was delivered through single-channel swivels (Instech, Plymouth Meeting, PA) by an infusion pump (model PHM-100; Med Associates). A computer controlled the infusion pumps and the behavioral software.

Experimental procedures. Rats were food deprived to $90 \%$ of their ad libitum weight and were trained to respond for food pellets during an 8 $\mathrm{hr}$ food-reinforced lever-training session. Subjects that demonstrated the ability to respond for food ( $\geq 100$ reinforced responses per session) were prepared for surgery; otherwise, an additional training session was conducted. After food training, the food hoppers were removed from the chambers and replaced with a metal plate. The rats were maintained on 25-35 gm of rat chow during the first $5 \mathrm{~d}$ of maintenance and then given access to chow ad libitum for the remainder of the experiment.

During $3 \mathrm{hr}$ sessions, a response on the right (active) lever resulted in an infusion of cocaine $\mathrm{HCl}(0.25 \mathrm{mg} / 0.05 \mathrm{ml})$ in the absence of any programmed environmental stimuli, followed by a $40 \mathrm{sec}$ time-out period. Responding during the time-out or on the left lever was recorded but resulted in no programmed consequences. After completing five successful daily sessions (i.e., 20 infusions in a $3 \mathrm{hr}$ session), rats underwent a single classical-conditioning session based on methods described previously (Kruzich et al., 2001). Before beginning the conditioning session, rats received bilateral intracranial infusions of either TTX (5.0 ng/side) or PBS vehicle in a $0.5 \mu$ l bolus ( $\mathrm{pH}$ of 7.0 for both) through 33 gauge injection cannulas. The injection cannulas extended $2 \mathrm{~mm}$ beyond the guide cannulas into the BLA or CeA. The infusion was delivered over 2 min by a microsyringe pump (Harvard Apparatus, Holliston, MA). The injection cannulas were left in place for an additional $1 \mathrm{~min}$ to allow for diffusion. The rats were then immediately placed into the chambers for the conditioning session. During this session, both levers were retracted, and rats received passive cocaine administration paired with $5 \mathrm{sec}$ presentations of a compound stimulus. The compound stimulus consisted of a light $(2.5 \mathrm{~W}, 24 \mathrm{~V}$ bulb) located above the retracted right lever and a tone $(78 \mathrm{~dB}, 2 \mathrm{kHz})$ delivered from a speaker on the front panel. A short-delay pairing format was used, whereby cocaine infusions were delivered during the last $2 \mathrm{sec}$ of the light plus tone presentation. The number of light plus tone-cocaine pairings was equal to the individual rat's intake of cocaine as averaged across the two previous sessions. After the conditioning session, rats received five additional self-administration sessions, in which cocaine was selfadministered in the absence of any programmed stimuli as before.

After the final self-administration session, rats underwent six daily extinction sessions (extinction phase 1). During extinction, responding was recorded but resulted in no programmed consequences. Rats then underwent a conditioned reinstatement test, during which they received response-contingent presentations of the light plus tone in the absence of cocaine. Before beginning this session, rats received bilateral TTX or vehicle using the same protocol described previously. The rats then

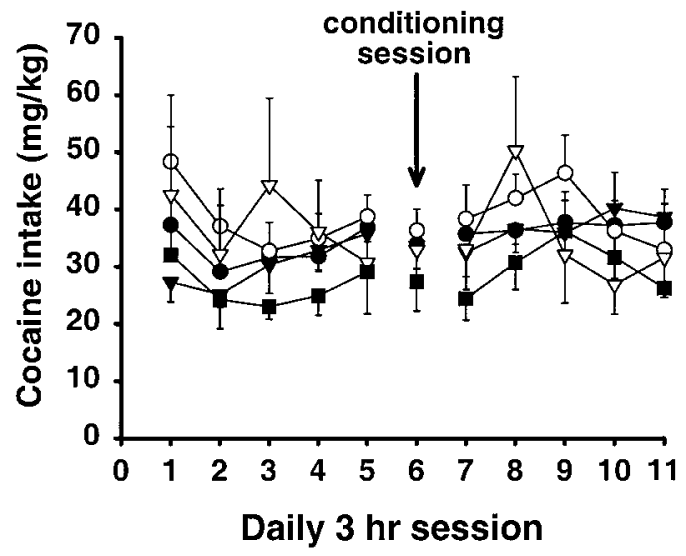

Figure 1. Cocaine intake (milligrams per kilograms per day) across daily $3 \mathrm{hr}$ sessions. Animals received cocaine on a fixed ratio 1 (FR1) schedule of reinforcement. Groups were as follows: control $(\bullet, n=12)$, BLA acquisition $(\bigcirc, n=9)$, BLA expression $(\boldsymbol{\nabla}, n=7)$, CeA acquisition $(\nabla$, $n=7)$, and CeA expression $(\boldsymbol{\square}, n=6)$. Acquisition or expression refers to the session in which TTX was administered in the BLA or CeA. The classical-conditioning session (acquisition) consisted of noncontingent delivery of intravenous cocaine infusions paired with discrete light plus tone presentation. No significant differences were seen between treatment groups.

underwent two additional extinction sessions (extinction phase 2). After extinction phase 2 , rats underwent a cocaine challenge test session. This test was used to determine whether previous infusions of TTX might have had persistent effects on ongoing behavior and whether they might possibly disrupt the pharmacological action of cocaine. Therefore, rats were not pretreated with TTX or vehicle before this test session. A noncontingent cocaine challenge test was used, because it has been demonstrated to reinstate lever responding in rodent models of relapse (de Wit and Stewart, 1981; Cornish and Kalivas, 2000). Ten minutes into the session, four passive intravenous cocaine infusions (dose range of $2.3-2.5 \mathrm{mg} / \mathrm{kg}$ ) were administered over $1 \mathrm{~min}$. Responding was recorded but had no programmed consequences.

Histological preparation. After all testing, rats received an overdose of Equithesin. Rats were then perfused with PBS followed by $10 \%$ formaldehyde. Brains were then extracted and stored in $10 \%$ formaldehyde. Coronal sections $(50 \mu \mathrm{m})$ were made using a vibratome, mounted onto gelatinized slides, and subsequently stained with cresyl violet. Placement of the cannulas was verified with a light microscope by an observer unaware of the individual subject's group assignment.

Data analysis. The average amount of self-administered cocaine (milligrams per kilograms per day) was determined for each session during the self-administration phase and analyzed using a two-way (group $\times$ session) repeated-measures ANOVA. For assessment of lever responding, both active (drug-paired right lever) and inactive (unpaired left lever) responses were recorded. Two-way repeated-measures ANOVAs were conducted to compare lever responding during cocaine selfadministration with extinction phase 1 , to compare extinction phase 1 with the conditioned reinstatement test, and to compare extinction phase 2 with the cocaine challenge test. After a significant ANOVA, pairwise comparisons using the Student-Newman-Keuls test were made.

\section{RESULTS}

Animals showed stable responding for cocaine during daily selfadministration (Fig. 1). There were no significant differences in the daily amount of self-administered cocaine between treatment groups $\left(F_{(4,36)}=2.11 ; p=0.10\right)$ or across sessions $\left(F_{(9,36)}=1.77\right.$; $p=0.08)$. The average cocaine intake $( \pm$ SEM $)$ was $34.98 \pm 1.54$ $\mathrm{mg} \cdot \mathrm{kg}^{-1} \cdot \mathrm{d}^{-1}$. Control animals (intracranial vehicle infusions only) did not show any significant differences between the BLA $(n=8)$ and the CeA $(n=4)$ for any session; thus, they were collapsed into a single control group.

Animals showed a significant decrease in active lever responding during extinction. Comparison of the last day of cocaine 

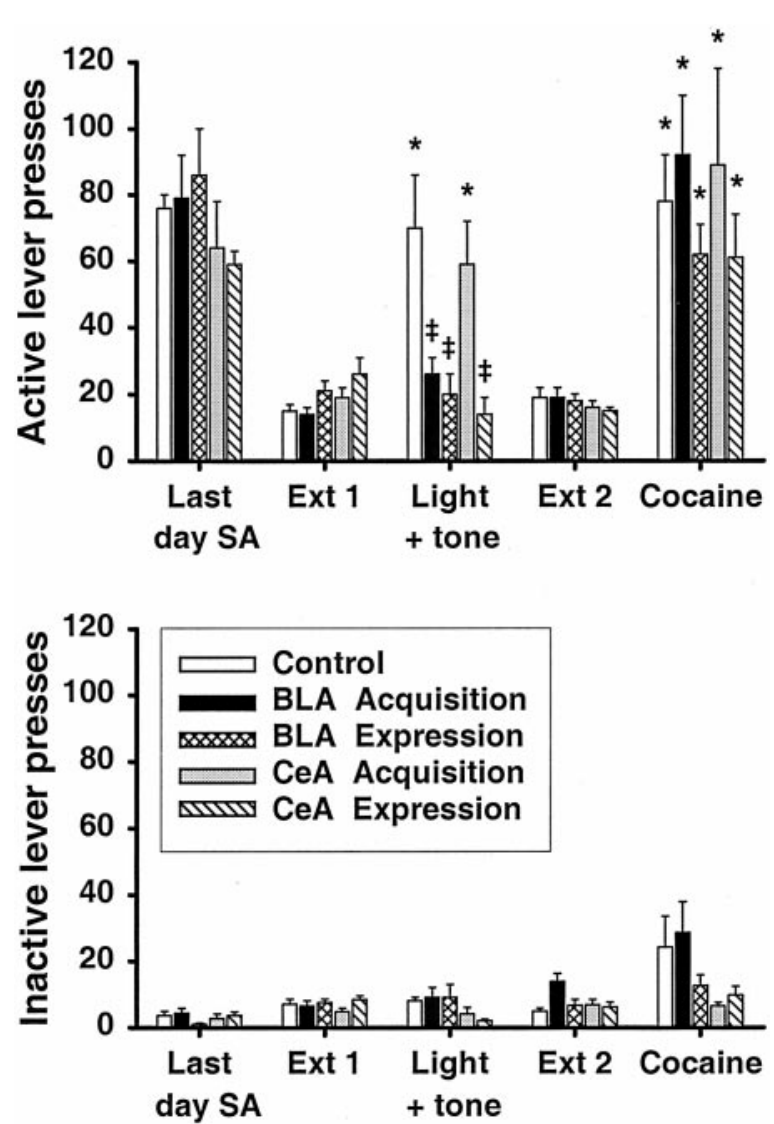

Figure 2. Lever responding during the last day of self-administration $(S A)$, extinction, and the reinstatement tests. Top, Responses (mean \pm SEM) on the active lever. For the conditioned reinstatement test (light plus tone), significantly increased responding over extinction phase 1 (Ext 1) was seen only in the Control and CeA Acquisition groups $\left({ }^{*} p<0.05\right.$; Student-Newman-Keuls test). The results for the other three treatment groups were significantly below control levels $(\ddagger p<0.05$; Student-Newman-Keuls test). For cocaine-primed reinstatement, noncontingent cocaine $(2.3-2.5 \mathrm{mg} / \mathrm{kg}$, i.v.) was delivered at the beginning of the session. Significantly increased responding over extinction phase 2 (Ext 2) was seen in all groups $\left({ }^{*} p<0.05\right.$; Student-Newman-Keuls test). Bottom, Responses on the inactive (left) lever.

self-administration and the last day of extinction phase 1 (Fig. 2, top) revealed a highly significant difference in active lever responding between the two test sessions $\left(F_{(1,36)}=123.73 ; p<\right.$ $0.001)$, with a significant decrease seen in each group $(p<0.05)$. However, there were no significant group differences in responding on the active lever during extinction phase 1 and the cocaine self-administration phase $\left(F_{(4,36)}=0.99 ; p=0.43\right)$, nor was there a significant group $\times$ test day interaction $\left(F_{(4,36)}=2.32 ; p=\right.$ 0.08). Conversely, responding on the inactive lever (Fig. 2, bottom) significantly increased during extinction phase 1 compared with the cocaine self-administration phase $\left(F_{(1,36)}=8.85 ; p<\right.$ $0.01)$. As with active lever responding, there were no significant group differences $\left(F_{(4,36)}=1.05 ; p=0.40\right)$ or group $\times$ test interactions $\left(F_{(4,36)}=0.48 ; p=0.75\right)$ for inactive lever responses.

Comparison of extinction and the conditioned reinstatement test (Fig. 2, top) revealed a significant difference in responding between the treatment groups $\left(F_{(4,36)}=2.75 ; p<0.05\right)$, a significant difference in responding between the two test sessions $\left(F_{(1,36)}=12.63 ; p<0.005\right)$, and a significant group $\times$ test session interaction $\left(F_{(4,36)}=6.48 ; p<0.001\right)$. TTX infusions into the BLA before the classical-conditioning trial (BLA acquisition) or

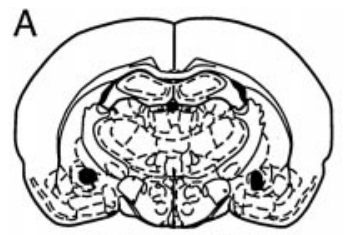

Bregma $-2.12 \mathrm{~mm}$

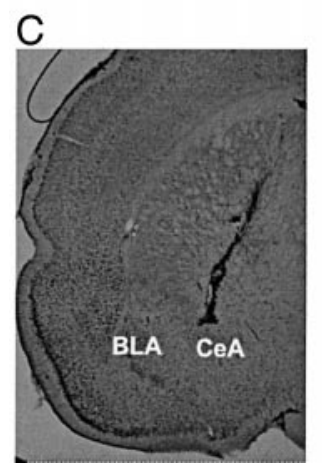

Figure 3. Intracranial infusion sites. A schematic representation of infusion cannula placement in the $\mathrm{CeA}(A)$ and $\mathrm{BLA}(B)$ from rats used in the final statistical analyses. $A$ and $B$ are adapted from Paxinos and Watson (1986). Representative photomicrographs are shown for the CeA $(C)$ and the BLA $(D)$.

into the BLA or CeA on the conditioned reinstatement test day (BLA expression and CeA expression) significantly attenuated responding for the light plus tone compared with the control and CeA acquisition groups $(p<0.05)$. For the inactive lever (Fig. 2, bottom $)$, there were no significant differences in responding between the groups $\left(F_{(4,36)}=1.08 ; p=0.38\right)$ or across test sessions $\left(F_{(1,36)}=0.12 ; p=0.73\right)$. Although there was a significant group $\times$ test day interaction $\left(F_{(4,36)}=3.11 ; p<0.05\right)$, there were no significant post hoc comparisons.

Cocaine-induced priming produced a significant increase in active lever responding (Fig. 2, top) over extinction phase 2 levels $\left(F_{(1,36)}=64.30 ; p<0.001\right)$, with each of the five groups showing a robust reinstatement $(p<0.05)$. There was no significant group effect $\left(F_{(4,36)}=0.57 ; p=0.68\right)$ or group $\times$ test interaction $\left(F_{(4,36)}=0.72 ; p=0.59\right)$. Responding on the inactive lever (Fig. 2 , bottom) revealed a significant increase in responding during the cocaine challenge relative to extinction phase 2 for all groups $\left(F_{(1,36)}=10.60 ; p<0.01\right)$, but no significant group differences $\left(F_{(4,36)}=1.36 ; p=0.27\right)$ or group $\times$ test interaction $\left(F_{(4,36)}=\right.$ $0.98 ; p=0.43)$.

Figure 3 depicts a schematic of inf usion cannula placement and photomicrographs of cannula placements from two subjects. The majority of tracts for the CeA were located in the medial CeA. Infusion tracts for the BLA were predominantly located in the interface between the lateral and the basal nuclei of the BLA complex. There was no evidence of lesion-like effects in the rats treated with either TTX or vehicle.

\section{DISCUSSION}

The current study examined the roles of the BLA and CeA in the acquisition and expression of conditioned reinstatement of responding for stimuli associated with cocaine administration. Infusions of TTX into the BLA, but not the CeA, before a discrete classical-conditioning session disrupted the acquisition of associative learning with a cocaine-paired cue. The process of attaching salience to environmental stimuli via the amygdala is believed to 
be initiated by activation of the lateral amygdala by thalamic and cortical nuclei (LeDoux, 2000). Thus, TTX infusion into the BLA in the present study likely disrupted the impulse conductance of efferent inputs from the thalamus and cortex that terminate in the BLA during acquisition. Several studies have reported that BLA infusions of glutamate receptor antagonists, such as CNQX or AP-5, prevent the acquisition but not the expression of responding to presentations of stimuli in conditioned aversion-learning tasks (Miserendino et al., 1990; Gewirtz and Davis, 1997). In addition, we have found recently that the expression of conditioned reinstatement of responding for a cocaine-paired stimulus is not disrupted by infusion of AP-5 or CNQX into the BLA (See et al., 2001), suggesting that glutamatergic synaptic input is involved in the acquisition but not necessarily the expression of associative learning mediated by the BLA.

It is unlikely that we inactivated the BLA while injecting TTX into the $\mathrm{CeA}$, because the rats from the $\mathrm{CeA}$ acquisition group would not have shown the robust reinstatement of responding for presentations of the light plus tone during the conditioned reinstatement test. Although these nuclei are close in proximity, it has been shown that the blocked area of neural tissue after a $0.5 \mu \mathrm{l}$ infusion of lidocaine is limited to a diameter of $0.9 \mathrm{~mm}$ (Sandkuhler et al., 1987), suggesting a relatively discrete spread of the infusion. However, in the absence of direct measurements of TTX diffusion, we cannot rule out the possibility that the BLA was affected by the spread of TTX from the CeA infusions.

The dissociation of TTX effects after inactivation of the BLA or the $\mathrm{CeA}$ before acquisition supports growing evidence for the differential roles of these two amygdalar nuclei in various conditioning tasks. In an aversive learning task, inhibition of the BLA by lidocaine immediately after inhibitory avoidance training impaired later retention performance, although infusions into the CeA were without effect (Parent and McGaugh, 1994). Using an evaluation of various stages of appetitive learning, Hess et al. (1997) evaluated c-fos mRNA levels across amygdala subregions during different stages of an odor discrimination task. When animals were transferred from unconditioned responding to conditioned cued responding, there was a pronounced shift to a high ratio of basolateral to medial amygdala nuclei c-fos mRNA labeling. The relative increase of basolateral to medial labeling was interpreted by these investigators, as suggesting a greater engagement of BLA neuronal activity during the conditioning task. Finally, the dissociation between BLA and CeA function in the present study is supported by measures of amygdalar regulation of synaptic plasticity (Ikegaya et al., 1994), in which lesions of the BLA, but not the CeA, attenuated hippocampal long-term potentiation, which is the most widely accepted physiological marker of learning.

In light of the known anatomical connectivity of the amygdala (Pitkanen, 2000), the blockade of expression of conditioned responding after BLA or CeA inactivation supports a sequential progression of stimulus processing and output signaling via a lateral to medial flow, as suggested for amygdalar regulation of fear conditioning (LeDoux, 2000). The excitatory innervation of the $\mathrm{CeA}$ is gated by both the lateral and basal amygdalar nuclei (McDonald, 1991; Royer et al., 1999), with CeA efferents then diffusely projecting to a number of forebrain and brainstem structures that are engaged in attention and motor activation (Pitkanen, 2000). In addition, there are reciprocal connections from the $\mathrm{CeA}$ to the BLA, and both amygdalar areas have extensive connections with areas implicated in drug addiction and relapse, including the nucleus accumbens (Koob et al., 1998) and orbitofrontal cortex (Porrino and Lyons, 2000).

Dopaminergic innervation of the amygdala has been demonstrated to be important in associative learning and in cellular firing patterns within the amygdala (Nader and LeDoux, 1999). It was found recently that increased extracellular dopamine (DA) in the BLA leads to increases in the firing of fast-spiking rate neurons, enhances excitatory input from the sensory association cortex, and decreases inhibitory input from limbic areas such as the medial prefrontal cortex (Rosenkranz and Grace, 1999). These investigators hypothesized that increased amygdalar DA may serve as a "sensory filter" by enabling enhanced processing of sensory stimuli via removal of mediodorsal thalamic and prefrontal cortical inhibition, allowing for what they have termed "sensory-driven affective responses." In support of this, we have found that infusions of the DA D1 antagonist SCH 23390 into the BLA severely disrupted the expression of conditioned reinstatement of responding (See et al., 2001). Stimuli associated with cocaine may attain affective value through the amygdala, because of the cocaine-induced increase in extracellular DA (TranNguyen et al., 1998; Weiss et al., 2000). Increased amygdalar DA would, in turn, lead to an enhanced signal from the BLA to the $\mathrm{CeA}$ and would subsequently increase $\mathrm{CeA}$ output to brainstem nuclei targets, such as the ventral tegmental area (Sun et al., 1994), which would further facilitate the dopaminergic innervation of the amygdala. The increased sensory-driven activation of the BLA would then lead to a greater activation of motor circuits involved in cocaine-seeking behavior (Pierce and Kalivas, 1997; Cornish and Kalivas, 2000).

In summary, our results provide the first assessment of neural circuitry in both the acquisition and the expression of drugassociated conditioned stimuli in a reinstatement model of relapse. The BLA is critical in the initial formation of discrete stimulus-drug associations as well as in the expression of cocaineseeking behavior activated by these learned associations. Processing of this information during reinstatement of drug seeking appears to depend on efferent outflow of the BLA via the CeA in a manner analogous to that seen in other types of affective learning (LeDoux, 2000), because expression is also blocked by $\mathrm{CeA}$ inactivation. This amygdala circuitry and its reciprocal innervations thus form part of the essential circuit of associative learning that underlies conditioned, cued relapse in drug abuse.

\section{REFERENCES}

Childress AR, Mozley PD, McElgin W, Fitzgerald J, Reivich M, O’Brien CP (1999) Limbic activation during cue-induced cocaine craving. Am J Psychiatry 156:11-18.

Cornish JL, Kalivas PW (2000) Glutamate transmission in the nucleus accumbens mediates relapse in cocaine addiction. J Neurosci 20:RC89 $(1-5)$.

de Wit H, Stewart J (1981) Reinstatement of cocaine-reinforced responding in the rat. Psychopharmacology 75:134-143.

Ehrman RN, Robbins SJ, Childress AR, O'Brien CP (1992) Conditioned responses to cocaine-related stimuli in cocaine abuse patients. Psychopharmacology 107:523-529.

Everitt BJ, Parkinson JA, Olmstead MC, Arroyo M, Robledo P, Robbins TW (1999) Associative processes in addiction and reward: the role of amygdala-ventral striatal subsystems. Ann NY Acad Sci 877:412-438.

Gallagher M, Graham PW, Holland PC (1990) The amygdala central nucleus and appetitive Pavlovian conditioning: lesions impair one class of conditioned behavior. J Neurosci 10:1906-1911.

Gewirtz JC, Davis M (1997) Second-order fear conditioning prevented by blocking NMDA receptors in amygdala. Nature 388:471-474.

Grant S, London ED, Newlin DB, Villemagne VL, Liu X, Contoreggi C, Phillips RL, Kimes AS, Margolin A (1996) Activation of memory circuits during cue-elicited cocaine craving. Proc Natl Acad Sci USA 93:12040-12045.

Grimm JW, See RE (2000) Dissociation of primary and secondary 
reward-relevant limbic nuclei in an animal model of relapse. Neuropsychopharmacology 22:473-479.

Han JS, Holland PC, Gallagher M (1999) Disconnection of the amygdala central nucleus and substantia innominata/nucleus basalis disrupts increments in conditioned stimulus processing in rats. Behav Neurosci 113:143-151.

Hatfield T, Han JS, Conley M, Gallagher M, Holland P (1996) Neurotoxic lesions of basolateral, but not central, amygdala interfere with Pavlovian second-order conditioning and reinforcer devaluation effects. J Neurosci 16:5256-5265.

Hess US, Gall CM, Granger R, Lynch G (1997) Differential patterns of c-fos mRNA expression in amygdala during successive stages of odor discrimination learning. Learn Mem 4:262-283.

Holland PC, Han JS, Gallagher M (2000) Lesions of the amygdala central nucleus alter performance on a selective attention task. J Neurosci 20:6701-6706.

Ikegaya Y, Saito H, Abe K (1994) Attenuated hippocampal long-term potentiation in basolateral amygdala-lesioned rats. Brain Res 656:157-164.

Koob GF, Sanna PP, Bloom FE (1998) Neuroscience of addiction. Neuron 21:467-476.

Kruzich P, Congleton K, See R (2001) A discrete classically-conditioned stimulus elicits operant drug-seeking behavior in an animal model of relapse. Behav Neurosci, in press.

LeDoux JE (2000) Emotion circuits in the brain. Annu Rev Neurosci 23:155-184.

McDonald AJ (1991) Topographical organization of amygdaloid projections to the caudatoputamen, nucleus accumbens, and related striatallike areas of the rat brain. Neuroscience 44:15-33.

Meil WM, See RE (1997) Lesions of the basolateral amygdala abolish the ability of drug-associated cues to reinstate responding during withdrawal from self-administered cocaine. Behav Brain Res 87:139-148.

Miserendino MJ, Sananes CB, Melia KR, Davis M (1990) Blocking of acquisition but not expression of conditioned fear-potentiated startle by NMDA antagonists in the amygdala. Nature 345:716-718.

Nader K, LeDoux JE (1999) Inhibition of the mesoamygdala dopaminergic pathway impairs the retrieval of conditioned fear associations. Behav Neurosci 113:891-901.

Parent MB, McGaugh JL (1994) Posttraining infusion of lidocaine into the amygdala basolateral complex impairs retention of inhibitory avoidance training. Brain Res 661:97-103.

Paxinos G, Watson D (1986) The rat brain in stereotaxic coordinates. New York: Academic.
Pierce RC, Kalivas PW (1997) A circuitry model of the expression of behavioral sensitization to amphetamine-like psychostimulants. Brain Res Brain Res Rev 25:192-216.

Pitkanen A (2000) Connectivity of the rat amygdaloid complex. In: The amygdala: a functional analysis, Ed 2 (Aggleton JP, ed), pp 31-115. Oxford: OUP

Porrino LJ, Lyons D (2000) Orbital and medial prefrontal cortex and psychostimulant abuse: studies in animal models. Cereb Cortex 10:326-333.

Robledo P, Robbins TW, Everitt BJ (1996) Effects of excitotoxic lesions of the central amygdaloid nucleus on the potentiation of reward-related stimuli by intra-accumbens amphetamine. Behav Neurosci 110:981-990.

Rosenkranz JA, Grace AA (1999) Modulation of basolateral amygdala neuronal firing and afferent drive by dopamine receptor activation in vivo. J Neurosci 19:11027-11039.

Royer S, Martina M, Pare D (1999) An inhibitory interface gates impulse traffic between the input and output stations of the amygdala. J Neurosci 19:10575-10583.

Sandkuhler J, Maisch B, Zimmermann M (1987) The use of local anaesthetic microinjections to identify central pathways: a quantitative evaluation of the time course and extent of the neuronal block. Exp Brain Res 68:168-178.

See RE, Grimm JW, Kruzich PJ (2001) Dopamine, but not glutamate, receptor blockade in the basolateral amygdala attenuates conditioned reward in a rat model of relapse to cocaine-seeking behavior. Psychopharmacology 154:301-310.

Sun N, Yi H, Cassell MD (1994) Evidence for a GABAergic interface between cortical afferents and brainstem projection neurons in the rat central extended amygdala. J Comp Neurol 340:43-64.

Tran-Nguyen LT, Fuchs RA, Coffey GP, Baker DA, O'Dell LE, Neisewander JL (1998) Time-dependent changes in cocaine-seeking behavior and extracellular dopamine levels in the amygdala during cocaine withdrawal. Neuropsychopharmacology 19:48-59.

Weiss F, Maldonado-Vlaar CS, Parsons LH, Kerr TM, Smith DL, BenShahar O (2000) Control of cocaine-seeking behavior by drugassociated stimuli in rats: effects on recovery of extinguished operantresponding and extracellular dopamine levels in amygdala and nucleus accumbens. Proc Natl Acad Sci USA 97:4321-4326.

Whitelaw RB, Markou A, Robbins TW, Everitt BJ (1996) Excitotoxic lesions of the basolateral amygdala impair the acquisition of cocaineseeking behaviour under a second-order schedule of reinforcement. Psychopharmacology (Berl) 127:213-224. 